\title{
Intra- and inter-laboratory evaluation of an improved multiplex-PCR method for detection and typing of Salmonella
}

\author{
Ilargi Martínez-Ballesteros ${ }^{1}$, Bianca Paglietti ${ }^{2}$, Aitor Rementeria ${ }^{1}$, Lorena Laorden ${ }^{1}$, Maria \\ García-Ricobaraza $^{1}$, Joseba Bikandi ${ }^{1}$, Salvatore Rubino ${ }^{2}$, Javier Garaizar ${ }^{1}$ \\ ${ }^{1}$ Department of Immunology, Microbiology and Parasitology, University of the Basque Country, Vitoria-Gasteiz, \\ Spain \\ ${ }^{2}$ Department of Biomedical Sciences, University of Sassari, Sassari, Italy
}

\begin{abstract}
Introduction: We developed and evaluated a multiplex-PCR method for rapid detection of the most common Salmonella serovars in both developed and developing countries. Additionally, the stability of the premixed reagents at high room temperature was studied.

Methodology: Fifty-two Salmonella strains belonging to the collections of the University of Sassari, Italy, and to the University of the Basque Country, Spain, and a collection of a hundred blinded strains, were used to evaluate the multiplex-PCR. Primers targeting genes STY1599 and $\mathrm{fliC}$ were selected, and the method was evaluated both intra and inter-laboratories.

Results: The inter-laboratory reproducibility was $95.92 \%$, with a kappa index of 0.757 that indicates a substantial agreement and a high accuracy $(80.81 \%)$. The sensitivity, specificity, accuracy and precision indexes for the Salmonella genus and $S$. Typhi targets were maximum, although the targets for Paratyphi A, Typhimurium and Enteritidis showed less accuracy. During a seven-week period, hot-start multiplexPCR runs were performed with reagents mixed with wax to test their stability at $30^{\circ} \mathrm{C}$, and no significant variation in the patterns of amplification was observed.

Conclusions: An improved multiplex-PCR for rapid detection of the most common serovars of Salmonella operable in both developed and developing countries has been designed and tested intra and inter-laboratories. Following a careful optimization protocol will not only allow the confirmation of any suspicious colony by the amplification of the Salmonella genus target, but also the preliminary adscription to the prevalent serovars. Premixed reagents with wax facilitate the throughput and stability of reagents at high room temperatures.
\end{abstract}

Key words: Salmonella; multiplex-PCR; Typhi; Paratyphi A; Enteritidis; Typhimurium

J Infect Dev Ctries 2012; 6(5):443-451.

(Received 01 December 2011 - Accepted 15 January 2012)

Copyright (C) 2012 Martinez-Ballesteros et al. This is an open-access article distributed under the Creative Commons Attribution License, which permits unrestricted use, distribution, and reproduction in any medium, provided the original work is properly cited

\section{Introduction}

Salmonella enterica is an important enteric pathogen which causes gastroenteritis and enteric fever in humans and is widely spread in nature. Outbreaks of Salmonella infections are frequently reported from developed and developing countries, as this pathogen spreads quickly through the water and the food chain [1]. Methodologies for Salmonella enterica subsp. enterica typing, which include phenotypical and genotypical techniques, have been recently revised by Wattiau et al. [2]. The investigation of Salmonella outbreaks employs serotyping as the first typing method based on the scheme developed by Kauffmann-White-Le Minor, which allows distinguishing more than 2,600 different serovars [3]. The use of Salmonella serotyping for several decades has provided researchers with the knowledge to better understand the global epidemiology of Salmonella and their spread at the ubiquitous reservoirs in nature. Nevertheless, the need for a large number of specific antisera and technical expertise for performing the serotyping restricts its use mainly to national reference laboratories. Furthermore, in most developed countries, serovars Enteritidis and Typhimurium represent the two most common isolated serovars from clinical samples, accounting for two thirds of the total isolated [1]. In developing countries, typhoidal Salmonella occupy the third position where serovars Typhi and Paratyphi A represent the most prevalent causes of typhoid fever in humans [1,4-6]. To overcome the handcrafted nature of classical serotyping and the high level of technical expertise it requires, alternative methods for the identification of serovars, such as 
DNA-based serotyping or "molecular serotyping" have been developed [2,7-10].

Salmonella enterica strains could be further discriminated in each serovar by the use of standardized epidemiological DNA based methods such as pulsed field gel electrophoresis (PFGE, which is considered the gold standard today), multi-locus variable number of tandem repeats analysis (MLVA), or multi-locus sequence typing (MLST) [11-13]. PCR based methods have also improved the speed and specificity required in epidemiological studies $[14,15]$. A variant of the PCR method called multiplex-PCR allows the simultaneous amplification of several targets in a single reaction, and it has been proved useful in a wide range of microbiological applications [16-27]. As the multiplex-PCR method could be limited by the amount of components that must be pre-mixed, careful optimization is required in order to obtain highly reproducible results. For the critical evaluation of any typing method, the Study Group on Epidemiological markers of the European Society of Clinical Microbiology and Infectious Diseases recommends the study of intra- and interlaboratories reproducibility, although it is not generally performed $[28,29]$.

In a previous study we developed a multiplexPCR method for the rapid detection of the most common Salmonella serovars causing gastroenteritis in Spain, but it lacked targets for typhoidal serovars [30]. Therefore, the aims of the present work are to show the improvement of the aforementioned discrimination of the multiplex-PCR by means of the addition of two new DNA targets for Salmonella serovars Typhi and Paratyphi A, to evaluate the intraand inter-laboratory reproducibility of the method, and to study the stability of the reagents at high room temperature, so that they could be used in limited equipped laboratories. These improvements might make this method suitable for the fast detection and typing of Salmonella in most laboratories.

\section{Methodology}

\section{Bacterial strains}

The bacterial strains used in this study included forty Salmonella enterica strains belonging to the collection of the Department of Biomedical Sciences, University of Sassari, Italy ( $S$. Typhi $[\mathrm{n}=16]$ and $S$. Paratyphi A $[\mathrm{n}=16]$ from blood samples, and $S$. Typhimurium, $S$. Enteritidis, $S$. Hadar, $S$. Infantis, $S$. Isangi, $S$. Blockley, $S$. Mbandaka and $S$.
Bovismorbificans strains recovered from food or environmental sources), twelve Salmonella strains (nine Salmonella 4,5,12:i:-, one $S$. Typhimurium, one $S$. Enteritidis and one $S$. Cremieu) recovered from clinical samples of patients suffering from gastroenteritis belonging to the collection of the Department of Immunology, Microbiology and Parasitology, University of Basque Country, Spain, and a collection of one hundred blinded strains provided by the Spanish Reference Center for Salmonella (SRCS) (Table 1). All the Salmonella strains tested have been previously serotyped following the Kauffmann-White-Le Minor Scheme [3]. Bacterial DNA was extracted using the boiling method or commercial kits as previously described $[14,15]$.

Design of DNA targets for detection of Salmonella serovars Typhi and Paratyphi A

To design new DNA targets for multiplex-PCR, the available published genome sequences of Salmonella Typhi and Paratyphi A serovars [31,32] were analyzed. Based on those databases and previous works, genes STY1599 and fliC, specific for $S$. Typhi [20], and phase one flagellar antigen of type "a" strains respectively, were selected. New primer pairs were designed, synthesized (Invitrogen, Monza, Italy), and added to the multiplex-PCR reaction mix together with previously designed primers (Table 2). Concentrations of all components for the PCR reaction were optimized in a final volume of $25 \mu 1$ with $0.25 \mathrm{mM}$ dNTPs, 1 U DyNAzyme (New England Biolabs, Ipswich, MA, USA), $1 \mu 1$ of 1:2.000 dilution of an internal amplification control DNA (IC) [30], and $2 \mu 1$ of crude lysate DNA. The thermocycling conditions were as follows: initial denaturation at $95^{\circ} \mathrm{C}$ for 2 minutes, followed by 30 cycles at $95^{\circ} \mathrm{C}$ for 1 minute, $57^{\circ} \mathrm{C}$ for 1 minute and $72^{\circ} \mathrm{C}$ for 2 minutes, and a final elongation step at $72^{\circ} \mathrm{C}$ for 5 minutes. All the reactions were performed using a thermocycler (MJ Research PTC-200 Thermo Cycler, Bio-Rad, Foster City, CA, USA). The PCR products were electrophoresed in $2 \%$ agarose gels in 1X TBE buffer, stained with ethidium bromide $(0.5 \mu \mathrm{g} / \mathrm{ml})$, and photographed under ultraviolet (UV) light. Gels were analysed to check the band profiles to assign a different numerical code for each positive band. A final code was obtained for each profile by the addition of all assigned numbers. 
Table 1. Strains tested in blinded study and multiplex-PCR results obtained in the accuracy experiments

\begin{tabular}{|c|c|c|c|c|c|c|c|c|c|c|c|c|}
\hline \multirow[t]{2}{*}{ Species tested } & \multirow[t]{2}{*}{ Serovar $(\mathrm{SRCS})^{\mathrm{a}}$} & \multirow[t]{2}{*}{$\begin{array}{l}\text { Sero } \\
\text { group }\end{array}$} & \multirow[t]{2}{*}{$\underset{\text { isolates }^{\mathrm{a}}}{N}$} & \multicolumn{8}{|c|}{ PCR results $(b p)^{b}$} & \multirow[t]{2}{*}{$\begin{array}{l}\text { Type } \\
\text { code }^{\text {c }}\end{array}$} \\
\hline & & & & $\begin{array}{l}102 \\
{[1]} \\
\end{array}$ & $\begin{array}{l}204 \\
{[2]} \\
\end{array}$ & $\begin{array}{c}237 \\
{[128]}\end{array}$ & $\begin{array}{c}304 \\
{[4]} \\
\end{array}$ & $\begin{array}{r}401 \\
{[8]} \\
\end{array}$ & $\begin{array}{l}502 \\
{[16]}\end{array}$ & $\begin{array}{r}607 \\
{[64]}\end{array}$ & $\begin{array}{c}705 \\
{[32]}\end{array}$ & \\
\hline \multirow{38}{*}{ S. enterica I } & Paratyphi A (2,12:a:-) & A & 5 & & + & & & & & + & & 66 \\
\hline & Agona $(4,12: f, g, s:-)$ & $\mathrm{B}$ & 4 & & + & & & & & & & 2 \\
\hline & Brandenburg $\left(4,12: 1, v: e, n, z_{15}\right)$ & $\mathrm{B}$ & 5 & & + & & & & & & & 2 \\
\hline & Coeln $(4,12: \mathrm{y}: 1,2)$ & $\mathrm{B}$ & $3^{\mathrm{d}}$ & & + & & & + & & & & 10 \\
\hline & Derby (4,5,12:f,g:-) & $\mathrm{B}$ & 5 & & + & & & & & & & 2 \\
\hline & Hessarek $(4,12: a: 1,5)$ & $\mathrm{B}$ & 1 & & + & & & & & + & & 66 \\
\hline & Paratyphi B $(4,5,12: b: 1,2)$ & $\mathrm{B}$ & 2 & & + & & & & & & & 2 \\
\hline & Typhimurium $(4,12: \mathrm{i}: 1,2)$ & $\mathrm{B}$ & 7 & & + & & & + & & & & 10 \\
\hline & Infantis $(6,7: \mathrm{r}: 1,5)$ & $\mathrm{C} 1-\mathrm{C} 4$ & 1 & & + & & & & & & & 2 \\
\hline & & & 1 & & + & & & + & & & & 10 \\
\hline & & & 2 & & + & & & & + & & & 18 \\
\hline & Mikawasima (6,7:y:e,n, $\left.z_{15}\right)$ & $\mathrm{C} 1-\mathrm{C} 4$ & 1 & & + & & & & & & & 2 \\
\hline & Ohio $(6,7: b: 1, w)$ & $\mathrm{C} 1-\mathrm{C} 4$ & 1 & & + & & + & & & & & 6 \\
\hline & Virchow $(6,7: r: 1,2)$ & $\mathrm{C} 1-\mathrm{C} 4$ & 3 & & + & & & & & & & 2 \\
\hline & & & 1 & + & + & & & & & & & 3 \\
\hline & Goldcoast $(6,8: r: 1, w)$ & $\mathrm{C} 2-\mathrm{C} 3$ & 2 & & + & & & & & & & 2 \\
\hline & & & 1 & + & + & & & & & & & 3 \\
\hline & & & 1 & & + & & & & + & & & 18 \\
\hline & Hadar $\left(6,8: z_{10}: e, n, x\right)$ & $\mathrm{C} 2-\mathrm{C} 3$ & 2 & & + & & & & & & & 2 \\
\hline & & & 1 & + & + & & & & & & & 3 \\
\hline & & & 2 & & + & & & & + & & & 18 \\
\hline & Dublin (9,12:g,p:-) & D1 & 3 & + & + & & & & & & & 3 \\
\hline & Enteritidis $(9,12: \mathrm{g}, \mathrm{m:-})$ & D1 & 6 & & + & & + & & & & & 6 \\
\hline & & & 1 & + & + & & & & & & & 3 \\
\hline & Napoli $\left(9,12: 1, z_{13}: e, n, x\right)$ & D1 & 1 & & + & & & & + & & & 18 \\
\hline & Ndolo $(9,12: \mathrm{d}: 1,5)$ & D1 & 3 & & + & & & & + & & & 18 \\
\hline & Panama $(9,12: 1, \mathrm{v}: 1,5)$ & D1 & 3 & & + & & & & & & & 2 \\
\hline & & & 2 & + & + & & & & & & & 3 \\
\hline & Sendai $(9,12: a: 1,5)$ & D1 & 1 & & + & & & & & + & & 66 \\
\hline & Typhi $(9,12,[V i]: d:-)$ & D1 & 6 & & + & + & & & & & & 130 \\
\hline & Anatum $(3,10: e, h: 1,6)$ & E1 & 5 & & + & & & & & & & 2 \\
\hline & London $(3,10: 1, \mathrm{v}: 1,6)$ & E1 & 4 & & + & & & & & & & 2 \\
\hline & Meleagridis $(3,10: \mathrm{e}, \mathrm{h}: 1, \mathrm{w})$ & E1 & 1 & & + & & & & & & & 2 \\
\hline & Tel-el-kebir $\left(13,23: \mathrm{d}: \mathrm{e}, \mathrm{n}, \mathrm{Z}_{15}\right)$ & G1-G2 & 1 & & + & & & & & & & 2 \\
\hline & Gaminara $(16: \mathrm{d}: 1,7)$ & I & 1 & & + & & & & & & & 2 \\
\hline & Cerro $\left(\underline{6}, \underline{14}, 18: \mathrm{z}_{4}, \mathrm{Z}_{23}:-\right)$ & $\mathrm{K}$ & 1 & + & + & & & & & & & 3 \\
\hline & Minnesota (21:b:e,n,x) & $\mathrm{L}$ & 1 & & + & & & & & & & 2 \\
\hline & Spartel $(21: \mathrm{d}: 1,5)$ & $\mathrm{L}$ & 1 & & + & & & & & & & 2 \\
\hline C. freundii & & & 1 & & - & & & & & & & 0 \\
\hline E. coli & & & 2 & & - & & & & & & & 0 \\
\hline K. pneumoniae & & & 1 & & - & & & & & $+^{\mathrm{e}}$ & & 0 \\
\hline S. flexneri & & & 1 & & - & & & & & & & 0 \\
\hline S. sonnei & & & 1 & & - & & & & & & & 0 \\
\hline Y. enterocolitica & & & 1 & & - & & & & & & & 0 \\
\hline$Y$. intermedia & & & 1 & & - & & & & & & & 0 \\
\hline
\end{tabular}

${ }^{\text {a }}$ Serovars, serogoups and numbers of isolates provided by the Spanish Reference Center for Salmonella (SRCS) to blinded study. In brackets shows the antigenic formula of each serovar.

${ }^{\mathrm{b}}$ Multiplex-PCR results obtained. The presence (+) of 102-, 204-, 237-, 304-, 401-, 502-, 607-, and 705-bp and the assigned numbers (shown in brackets),

respectively. The symbol (-) in the band of 204-bp indicate that these isolates were not Salmonella.

${ }^{\mathrm{c}}$ After the positive detection of the Salmonella sp. band (204-bp), the type code is obtained by adding all the assigned numbers to positive amplicons.

${ }^{\mathrm{d}}$ One of three isolates of Coeln serovar was not amplified in the Italy Laboratory, and the multiplex -PCR was inhibited. However, in the Spanish Laboratory the three isolates of this serovar shown the same amplification pattern.

${ }^{\mathrm{e}}$ In Klebsiella pneumoniae it was detected one amplicon of 607-bp (amplicon assigned to Paratyphi A serovars). 
Study of inter-laboratory reproducibility and accuracy of the multiplex-PCR

Once the improved multiplex-PCR protocol was optimized an intra- and inter-laboratory agreement study was conducted to assess their accuracy and reproducibility. For these purposes, one hundred bacterial DNA samples provided by the Spanish Reference Center for Salmonella (SRCS) were tested by both the University of the Basque Country (Vitoria-Gasteiz, Spain) and the University of Sassari (Sassari, Italy). Each laboratory performed the improved multiplex-PCR following the previously described and agreed upon protocol, which included guidelines for gel analysis. However, each laboratory employed its own reagents and the equipment optimal for its setting.

\section{Stability of reagents at high room temperature}

A study for the determination of stability of PCR reagents at middle and high room temperature during storage was performed. For this purpose, premixes with PCR reagents were prepared in the Spanish laboratory. All the PCR reagents were mixed in a 0.2 $\mathrm{ml}$ Eppendorf tube, except for the bacterial DNA and the Taq polymerase (Amersham Biosciences, GE Healthcare Europe GmbH, Barcelona, SPAIN), and then sealed by adding a single bead of AmpliWax PCR Gem 50 (Applied Biosystems, Foster City, CA, USA) that was heated at $80^{\circ} \mathrm{C}$ for 10 minutes until it melted and formed a layer which solidified upon cooling. When multiplex-PCR was going to be performed, the missing reagents (DNA and Taq polymerase) were added onto this wax layer to start the reaction. PCR heating in the first denaturation step melted the wax, allowing all the reagents to mix and the amplification to begin. The tubes prepared with wax were stored for seven weeks at $30^{\circ} \mathrm{C}$ until it was time to begin the PCR reagents stability study. Every five days multiplex-PCR was performed, adding $2 \mu 1$ of crude lysate DNA of Salmonella serovars Enteritidis, Typhimurium, Cremieu and monophasic variant [4,5,12:i:-], and $1 \mathrm{U}$ of Taq polymerase.

\section{Statistical analysis}

Statistical analysis was performed using DAG_Stat developed by Macinnon [33]. This Excel table allows calculating the sensibility, the specificity, the accuracy (efficiency), the predictive positive (precision) and negative values of the test, and the Cohen's kappa index. The reproducibility of results was calculated as indicated by the European Study Group on Epidemiology Markers (ESGEM) $[28,29]$.

\section{Results}

Design of new PCR targets for serovars Typhi and Paratyphi $A$

Genes STY1599 and $f l i C$ were selected as PCR targets for detection of serovars Typhi and Paratyphi A, respectively. New primers were designed to amplify an internal $237 \mathrm{bp}$ DNA fragment for gen STY1599 and 607 bp for gen fliC. Both primers were added to previously developed multiplex-PCR for Salmonella molecular typing [30]. Excellent sensitivity and specificity were obtained, both in single reaction and multiplex-PCR reactions, when the collection of 40 strains from the University of Sassari was screened. However, as the improved multiplex-PCR included a total of eight pairs of primers and an internal amplification control DNA, careful optimization of all reaction components was required to obtain good intra-assay reproducibility. The final optimized concentration of all primers is shown in Table 2, the optimized concentration of other components was collected in the methodology, and the multiplex-PCR DNA profiles obtained in the optimization study are shown in Figure 1A.

Inter-laboratory reproducibility and accuracy of the improved multiplex-PCR

The use of the improved protocol in both laboratories gained an inter-laboratory reproducibility $95.92 \%$, with a Cohen's kappa index of 0.757 that indicates a substantial agreement. The results obtained from multiplex PCR in the University of Sassari and their associations with the final serovar data provided by the SRCS are shown in Table 1 . Comparison of both methods reached a high accuracy $(80.81 \%)$. The target-bytarget analysis of the results (Table 3), the amplification of the internal amplification control DNA, and the presence or absence of the specific band for Salmonella genus (200 bp) allowed the confirmation of all the Salmonella and the non-Salmonella strains. The sensitivity, specificity, accuracy and precision indexes of this Salmonella genus target were maximum (1.000). Only one PCR reaction was inhibited, as denoted by the absence of amplification bands of both the Salmonella genus and the IC. The target for $S$. Typhi was successfully detected in all Typhi strains investigated, so that specificity, accuracy and precision values were also maximum (1.000). Other targets showed weaker results, as shown in Table 3. The target for Paratyphi A was detected in all the $S$. Paratyphi A strains tested and additionally in one strain of serovar Sendai and Hessarek, both with an 
Figure 1. Multiplex-PCR amplification profiles

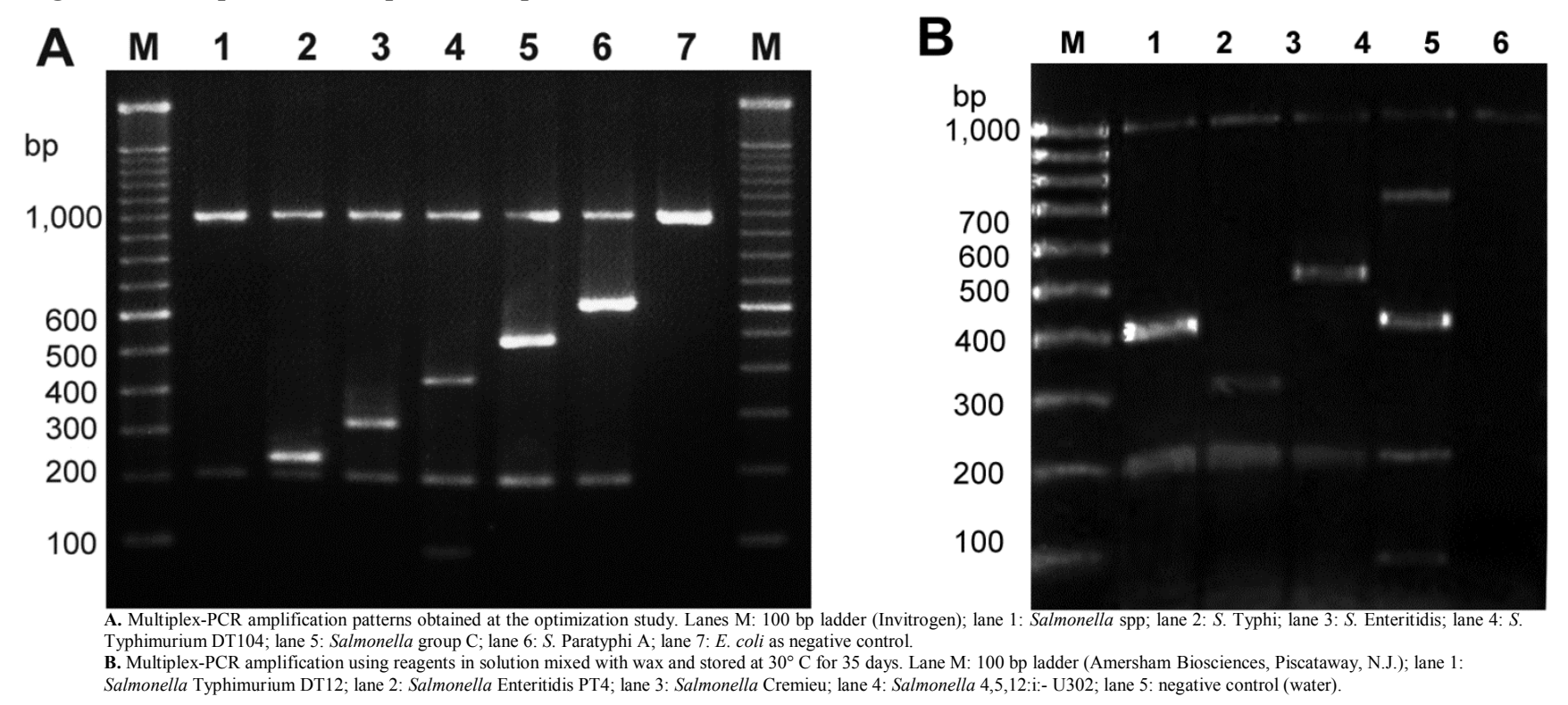

"a" antigen. Interestingly, a Klebsiella pneumoniae control strain also gave a positive reaction for this band. When Typhimurium serovar was analyzed, the seven $S$. Typhimurium strains were successfully detected, but also one Infantis and three Coeln serovar strains. The Enteritidis target was detected in six of the seven $S$. Enteritidis serovar strains, as well as in one Ohio serovar strain.

We encountered assignment problems with both the $502 \mathrm{bp}$ band and with the band of $102 \mathrm{bp}$, linked to the phage types DT104 and U302 of $S$. Typhimurium. The $502 \mathrm{bp}$ band, previously linked with $\mathrm{C} 2$ serogroup strains, was also detected in three C2-C3 serogroup Salmonella strains (two S. Hadar and one $S$. Goldcoast), in four D1 serogroup strains (three $S$. Ndolo and one $S$. Napoli) and in two C1-C4 serogroup strains ( $S$. Infantis). On the other hand, none of the DT104/U302 S. Typhimurium strains were identified in the blinded collection, but the 102 bp band, previously linked with the phage types DT104 and U302 of the $S$. Typhimurium band, was detected in ten Salmonella strains (three Dublin, two Panama, and one of Enteritidis, Cerro, Goaldcoast, Hadar and Virchow, respectively). As there were no Spanish $S$. [4,5,12:i:-] monophasic serovar strains in the blinded collection, the $705 \mathrm{bp}$ specific band for this serovar was not detected. It was later confirmed that the improved method successfully detected nine of such strains tested at the University of the Basque Country in Spain.
If we excluded from this blinded study the identification results obtained with the bands of serogroup C2 and DT104/U302, the accuracy of the identification obtained with the improved multiplexPCR versus the final serovar data provided by the SRCS was 0.929 and the Cohen's kappa index 0.658, which indicates a substantial agreement.

\section{Stability of reagents at room temperature}

During a seven-week period hot-start multiplexPCR runs were performed with reagents mixed with wax to test the stability of the premixed reagents at $30^{\circ} \mathrm{C}$. No significant variation in the patterns of amplification obtained over time was observed (Figure 1B), reaching a reproducibility of $100 \%$. Nevertheless, it was noticed that the band of $304 \mathrm{bp}$, specific for Salmonella enterica serovar Enteritidis, was not always clearly observed.

\section{Discussion}

The serology scheme developed in 1934 by Kauffmann and White has provided invaluable knowledge about the distribution of Salmonella worldwide, and still represents a cornerstone for the investigation of outbreaks of infections caused by this microorganism [1,3]. Nevertheless, due the difficulties to maintain a broad collection of anti-sera for serotyping, the technique is mainly performed by reference laboratories. For this reason, several efforts have been made recently to develop simpler 
Table 2. Primer sequences and lengths of PCR-amplified targets of Salmonella enterica serovars

\begin{tabular}{|c|c|c|c|c|c|}
\hline Primers & Sequence 5'-3' & Amplification target & $\begin{array}{c}\text { Amplicon } \\
\text { length } \\
\text { (bp) }\end{array}$ & [Final] $\mathbf{n M}$ & Reference \\
\hline $104-\mathrm{F}$ & ATGCGTTTGGTCTCACAGCC & \multirow{2}{*}{$\begin{array}{l}\text { Typhimurium phage types DT104 } \\
\text { and U302 }\end{array}$} & \multirow[t]{2}{*}{102} & 100 & \multirow[t]{2}{*}{30} \\
\hline 104-R & GCTGAGGCCACGGATATTTA & & & 75 & \\
\hline OMPC-F & ATCGCTGACTTATGCAATCG & \multirow[t]{2}{*}{ Salmonella genus } & \multirow[t]{2}{*}{204} & 50 & \multirow[t]{2}{*}{30} \\
\hline OMPC-R & CGGGTTGCGTTATAGGTCTG & & & 50 & \\
\hline STY-F & CCTTCTGCAGTGGTTTCCAT & \multirow[t]{2}{*}{ Typhi } & \multirow[t]{2}{*}{237} & 100 & \multirow[t]{2}{*}{ this study } \\
\hline STY-R & GATTACCCCACAGGAAGCAC & & & 100 & \\
\hline ENT-F & TGTGTTTTATCTGATGCAAGAGG & \multirow[t]{2}{*}{ Enteritidis } & \multirow[t]{2}{*}{304} & 100 & \multirow[t]{2}{*}{30} \\
\hline ENT-R & TGAACTACGTTCGTTCTTCTGG & & & 125 & \\
\hline TYPH-F & TTGTTCACTTTTTACCCCTGAA & \multirow[t]{2}{*}{ Typhimurium } & \multirow[t]{2}{*}{401} & 100 & \multirow[t]{2}{*}{30} \\
\hline TYPH-R & CCCTGACAGCCGTTAGATATT & & & 100 & \\
\hline HAD-F & ACCGAGCCAACGATTATCAA & \multirow[t]{2}{*}{ Serogroup C2-C3 } & \multirow[t]{2}{*}{502} & 100 & \multirow[t]{2}{*}{30} \\
\hline HAD-R & AATAGGCCGAAACAACATCG & & & 100 & \\
\hline SPA-F & CAGTCTGCTAACAGCACCAA & \multirow[t]{2}{*}{ Paratyphi A } & \multirow[t]{2}{*}{608} & 100 & \multirow[t]{2}{*}{ this study } \\
\hline SPA-R & GTCACATGGGCAGCAGTCA & & & 100 & \\
\hline $4512-\mathrm{F}$ & CGCTGTGGTGTAGCTGTTTC & \multirow[t]{2}{*}{ Serovar 4,5,12:i:- } & \multirow[t]{2}{*}{705} & 100 & \multirow[t]{2}{*}{30} \\
\hline $4512-\mathrm{R}$ & TCTGCCACTTCTTCACGTTG & & & 100 & \\
\hline
\end{tabular}

Table 3. Statistical analysis of results obtained in University of Sassari, Italy, with the different targets included in the multiplex PCR

\begin{tabular}{lccccccc} 
& \multicolumn{7}{c}{ Statistical index } \\
\cline { 2 - 8 } & Sensitivity & Specificity & Accuracy & $\begin{array}{c}\text { Predictive } \\
\text { value of } \\
\text { positive test }\end{array}$ & $\begin{array}{c}\text { Predictive } \\
\text { value of } \\
\text { negative test }\end{array}$ & $\begin{array}{c}\text { False } \\
\text { positive }\end{array}$ & $\begin{array}{c}\text { False } \\
\text { negative }\end{array}$ \\
\hline Salmonella genus & 1.000 & 1.000 & 1.000 & 1.000 & 1.000 & 0.000 & 0.000 \\
S. Typhi & 1.000 & 1.000 & 1.000 & 1.000 & 1.000 & 0.000 & 0.000 \\
S. Paratyphi A & 1.000 & 0.977 & 0.978 & 0.714 & 1.000 & 0.023 & 0.000 \\
S. Typhimurium & 1.000 & 0.964 & 0.967 & 0.700 & 1.000 & 0.036 & 0.000 \\
S. Enteritidis & 0.857 & 0.988 & 0.978 & 0.8571 & 0.988 & 0.012 & 0.143 \\
S. C2 serogroup & 0.333 & 0.927 & 0.868 & 0.333 & 0.927 & 0.073 & 0.667 \\
\hline
\end{tabular}

Note: to calculate statistics we used DAG_Stat (Macinnon, 2000)

*Several targets of multiplex-PCR were not included in these calculations as the DNA collection send by the SRCS did not incorporated strains with these targets

Also named Precision 
molecular tools that could provide a rapid detection method for clinical and food laboratories [2,7-10]. Such methods could help to shorten the detection time of local outbreaks of infection, prior to sending the strains to a reference laboratory for confirmation and further research. The multiplex-PCR method has proven to be a reliable and rapid molecular method for the detection of multiple pathogens in a single experiment [16-27]. In this direction, we previously developed a multiplex-PCR assay able to detect the most common serovars of Salmonella responsible of gastroenteritis in Spain [30]. Nevertheless, the method lacked PCR targets for typhoidal Salmonella which are prevalent in developing countries.

In this work, we modified our previous multiplexPCR method by the addition of two new targets, analyzed the intra- and inter-laboratory reproducibility and its accuracy, and studied the effect of elevated room temperatures on the reaction mix with wax, to facilitate a possible broader use of this new multiplex-PCR protocol in less equipped labs. We included new DNA targets, STY1599 and fliC, for serovars Typhi and Paratyphi A, respectively. Previously, STY1599 was observed as specific for the Typhi serovar [20]. A high specificity and sensitivity of modified multiplex-PCR can be claimed since we validated the method against a collection of 40 strains of Salmonella from different geographical origins.

The use of an IC helps researchers to determine whether a negative result is a true negative or is due to an inhibition of the PCR itself. The IC used in this work was previously described [30] and it is amplified with the same primers involved at the reaction and has to compete with them to become amplified. An important step at the inter-laboratory reproducibility stage was the strict adherence to the guidelines for gel analysis interpretation. For example, when the amount of DNA loaded in the gel was high some weak bands could be interpreted as real bands, with the consequent drop of the reproducibility. The use of agreed protocols allowed the inter-laboratory reproducibility of our assay to reach $95 \%$.

In terms of accuracy and precision, the improved multiplex-PCR performed well for both Salmonella genus detection and some serovar detection. Full concordance with the data of SRCS was observed when the Salmonella genus and Typhi serovar were analyzed. However, the target used to detect other serovars showed lower accuracy due to amplification with other Salmonella serovar. Two serovars (Hessarek and Sendai) amplified for the $S$. Paratyphi
A target (fliC gene). When these results were analyzed, it was revealed that these serovars shared the type "a" phase one flagellar antigen. As the $f l i C$ gene is responsible for the type "a" flagellar antigen of phase one, all strains of this group amplified with the primers designed for its detection. Recently, the reactivity was confirmed with strains of other serovars belonging to the same flagellar antigen. As we demonstrated in Alvarez et al. [30], the band assigned to Typhimurium serovar (of $401 \mathrm{bp}$ ) could be also detected in other serovars. The data obtained in this work confirmed this circumstance: one $S$. Infantis and three $S$. Coeln serovar strains of the blinded group gave this amplification band. One strain of $S$. Ohio serovar showed the $304 \mathrm{bp}$ band assigned to the Enteritidis serovar, and in one case this was weak and was assigned to one $S$. Derby serovar strain in the University of the Basque Country laboratory, causing incorrect classification of the serovar. Therefore, the presence in the gel of the bands designed for specific detection of $S$. Paratyphi A, $S$. Enteritidis or $S$. Typhimurium do not fully ensure their presence in the sample; on the contrary, their absence ensures they are not present in the sample. The $102 \mathrm{bp}$ and $502 \mathrm{bp}$ bands, associated with phage types DT104 and U302 of $S$. Typhimurium and serogroup C2-C3 respectively, were detected also in other serovars. When these bands were excluded from the analysis, the data reached a sufficient level of accuracy. Although new experiments need to be performed to select more suitable PCR targets for that purpose, the multiplexPCR set up in this study has shown to be powerful and easily adaptable. In the future, rapid whole genome sequencing technologies would help to discover better PCR targets and track food-borne illness [34].

Finally, we analyzed the effect of high temperature on the stability of the pre-mixed solution for hot-start procedures using wax [35]. The preparation of premixes with the 16 different primers and all the required reagents apart from the Taq polymerase and the bacterial DNA greatly facilitated the throughput of the technique. Furthermore, we demonstrated that the premixes are stable at high room temperature for several weeks. The control of temperature is a crucial element in developing countries, and consequently the stability observed during storage of the premixes could be helpful for the maintenance of the quality of the multiplex-PCR reagents. 
In conclusion, an improved multiplex-PCR for the rapid detection of the most common serovars of Salmonella operable in both developed and developing countries has been designed and tested intra- and inter-laboratories. Utilization of a careful optimization protocol not only allows the confirmation of any suspicious colony by the amplification of the Salmonella genus target, but also the preliminary assignment of the colony to the prevalent serovars. Premix reagents stabilized with wax facilitates the throughput and stability of reagents. As a result, the improved multiplex-PCR could be recommended for the early detection of the prevalent Salmonella serovars, both in developing and developed countries.

\section{Acknowledgements}

We thank Anabel Gilbert and Sara Arbulu for their excellent technical support. We also thank Silvia Herrera, from the Spanish Reference Center for Salmonella (National Center of Microbiology, Majadahonda, Madrid), for supplying the blinded strain collection and their serovar classification, and Prof. Alvin Fox for the English revision of the manuscript. The study was partly supported by the UPV/EHU GIU0820 and UFI 11/25, Basque Government IT343-10, and S-PC09UN04 (Saiotek) grants. I. MartínezBallesteros and L. Laorden were supported by Pre-doctoral Research Grants from the UPV/EHU of Spain.

\section{References}

1. Hendriksen RS, Vieira AR, Karlsmose S, Lo Fo Wong DM, Jensen AB, Wegener HC, Aarestrup FM (2011) Global monitoring of Salmonella serovar distribution from the World Health Organization Global Foodborne Infections Network Country Data Bank: results of quality assured laboratories from 2001 to 2007. Foodborne Pathog Dis 8: $887-900$

2. Wattiau P, Boland C, Bertrand S (2011) Methodologies for Salmonella enterica subsp. enterica subtyping: gold standards and alternatives. Appl Environ Microbiol 77: 7877-7885.

3. Guibourdenche M, Roggentin P, Mikoleit M, Fields PI, Bockemühl J, Grimont PAD, Weill FX (2010) Supplement 2003-2007 (No. 47) to the White-Kauffmann-Le Minor scheme. Res Microbiol 161: 26-29.

4. Fashae K, Ogunsola F, Aarestrup FM, Hendriksen RS (2010) Antimicrobial susceptibility and serovars of Salmonella from chickens and humans in Ibadan, Nigeria. J Infect Dev Ctries 4: 484-494.

5. Pokharel BM, Koirala J, Dahal RK, Mishra SK, Khadga PK, Tuladhar NR (2006) Multidrug-resistant and extendedspectrum beta-lactamase (ESBL)-producing Salmonella enterica (serovars Typhi and Paratyphi A) from blood isolates in Nepal: surveillance of resistance and a search for newer alternatives. Int J Infect Dis 10: 434-438.

6. Kumar Y, Sharma A, Mani KR (2011) Re-emergence of susceptibility to conventionally used drugs among strains of
Salmonella Typhi in central west India. J Infect Dev Ctries 5: 227-230.

7. Franklin K, Lingohr EJ, Yoshida C, Anjum M, Bodrossy L, Clark CG, Kropinski AM, Karmali MA (2011) Rapid genoserotyping tool for classification of Salmonella serovars. J Clin Microbiol 49: 2954-2965.

8. Suo B, He Y, Paoli G, Gehring A, Tu SI, Shi X (2010) Development of an oligonucleotide-based microarray to detect multiple foodborne pathogens. Mol Cell Probes 24: 77-86.

9. Mertes F, Biens K, Lehrach H, Wagner M, Dahl A (2010) High-throughput Universal Probe Salmonella Serotyping (UPSS) by nanoPCR. J Microbiol Methods 83: 217-223.

10. Fang NX, Huang B, Hiley L, Bates J, Savill J (2011) A rapid multiplex DNA suspension array method for Salmonella typhimurium subtyping using prophage-related markers. J Microbiol Methods (in press).

11. Pang JC, Chiu TH, Helmuth R, Schroeter A, Guerra B, Tsen HY (2007) A pulsed field gel electrophoresis (PFGE) study that suggests a major world-wide clone of Salmonella enterica serovar Enteritidis. Int J Food Microbiol 116: $305-$ 312.

12. Tankouo-Sandjong B, Sessitsch A, Liebana E, Kornschober C, Allerberger F, Hächler H, Bodrossy L (2007) MLST-v, multilocus sequence typing based on virulence genes, for molecular typing of Salmonella enterica subsp. enterica serovars. J Microbiol Methods 69: 23-36.

13. Liu WB, Liu B, Zhu XN, Yu SJ, Shi XM (2011) Diversity of Salmonella isolates using serotyping and multilocus sequence typing. Food Microbiol 28: 1182-1189.

14. Garaizar J, López-Molina N, Laconcha I, Baggesen DL, Rementeria A, Vivanco A, Audicana A, Perales I (2000) Suitability of PCR fingerprinting, Infrequent-Restriction-Site PCR, and Pulsed-Field Gel Electrophoresis, combined with computerized gel analysis, in library typing of Salmonella enterica serovar Enteritidis. Appl Environ Microbiol 66: 5273-5281.

15. Laorden L, Herrera-León S, Martínez I, Sanchez A, Kromidas L, Bikandi J, Rementeria A, Echeita A, Garaizar J (2010) Genetic evolution of the spanish multidrug-resistant Salmonella enterica 4,5,12:i:- monophasic variant. J Clin Microbiol 48: 4563-4566.

16. Caliendo AM (2011) Multiplex PCR and emerging technologies for the detection of respiratory pathogens. Clin Infect Dis 52 Suppl 4: 326-330.

17. Liu B, Zhang L, Zhu X, Shi C, Chen J, Liu W, He X, Shi X (2011) PCR identification of Salmonella serogroups based on specific targets obtained by comparative genomics. Int $\mathrm{J}$ Food Microbiol 144: 511-518.

18. Echeita MA, Herrera S, Garaizar J, Usera MA (2002) Multiplex PCR-based detection and identification of the most common Salmonella second-phase flagellar antigens. Res Microbiol 153: 107-113.

19. Guimarães C, Santana AP, Caldeira PH, Picão VS, Ferreira MA, Gonçalves FA, Murata LS, Perecmanis S (2010) PCR multiplex for detection of Salmonella Enteritidis, Typhi and Typhimurium and occurrence in poultry meat. Int $\mathrm{J}$ Food Microbiol 139: 15-22.

20. Park SH, Kim HJ, Cho WC, Kim JH, Oh MH, Kim SH, Lee BK, Ricke SC, Kim HY (2009) Identification of Salmonella enterica subspecies I, Salmonella enterica serovars Typhimurium, Enteritidis and Typhi using multiplex PCR. FEMS Microbiol Lett. 301: 137-146. 
21. Akiba M, Kusumoto M, Iwata T (2011) Rapid identification of Salmonella enterica serovars, Typhimurium, Choleraesuis, Infantis, Hadar, Enteritidis, Dublin and Gallinarum, by multiplex PCR. J Microbiol Methods 85: 915.

22. Ngan GJY, Ng LM, Lin RTP, Teo WP (2010) Development of a novel multiplex PCR for the detection and differentiation of Salmonella enterica serovars Typhi and Paratyphi A. Res Microbiol 161: 243-248.

23. Pui CF, Wong WC, Chai LC, Lee HY, Noorlis A, Zainazor TC, Tang JYH, Ghazali FM, Cheah YK, Nakaguchi Y, Nishibuchi M, Radu S (2011) Multiplex PCR for the concurrent detection and differentiation of Salmonella spp., Salmonella Typhi and Salmonella Typhimurium. Trop Med Health 39: 9-15.

24. Izumiya $\mathrm{H}$, Matsumoto $\mathrm{K}$, Yahiro $\mathrm{S}$, Lee $\mathrm{J}$, Morita $\mathrm{M}$, Yamamoto S, Arakawa E, Ohnishi M (2011) Multiplex PCR assay for identification of three major pathogenic Vibrio spp., Vibrio cholerae, Vibrio parahaemolyticus, and Vibrio vulnificus. Mol Cell Probes 25: 174-176.

25. Rajtak U, Leonard N, Bolton D, Fanning S (2011) A realtime multiplex SYBR Green I polymerase chain reaction assay for rapid screening of Salmonella serotypes prevalent in the European Union. Foodborne Pathog Dis 8: 769-780.

26. Bugarel M, Granier SA, Weill FX, Fach P, Brisabois A (2011) A multiplex real-time PCR assay targeting virulence and resistance genes in Salmonella enterica serotype Typhimurium. BMC Microbiol 11: 151.

27. Amaglia G, Omiccioli E, Brandi G, Bruce IJ, Magnani M (2010) A multiplex magnetic capture hybridization and multiplex Real-time PCR protocol for pathogen detection in seafood. Food Microbiol 27: 580-585.

28. Struelens MJ, Bauernfeind A, van Belkum A, Blanc D, Cookson BD, Dijkshoorn L, El Solh N, Etienne J, Garaizar J, Gerner-Smidt P, Legakis N, de Lencastre H, Nicolas MH, Pitt TL, Römling U, Rosdahl V, Witte W, and the Members of the European Study Group on Epidemiological Markers (ESGEM) of the European Society for Clinical Microbiology and Infectious Diseases (ESCMID) (1996) Consensus guidelines for appropriate use and evaluation of microbial epidemiologic typing systems. Clin Microbiol Infect 2: 2-11.

29. van Belkum A, Tassios P, Dijkshoorn L, Haeggman S, Cookson B, Fry NK, Fussing V, Green J, Feil E, GernerSmidt P, Brisse S, and Struelens M for the European Society of Clinical Microbiology and Infectious Diseases (ESCMID) Study Group on Epidemiological Markers (ESGEM) (2007) Guidelines for the validation and application of typing methods for use in bacterial epidemiology. Clin Microbiol Infect 13 Suppl 3: 1-46.
30. Alvarez J, Sota M, Vivanco AB, Perales I, Cisterna R, Rementeria A, Garaizar J (2004) Development of a multiplex PCR technique for detection and epidemiological typing of Salmonella in human clinical samples. J Clin Microbiol 42: 1734-1738.

31. Parkhill J, Dougan G, James KD, Thomson NR, Pickard D, Wain J, Churcher C, Mungall KL, Bentley SD, Holden MT, Sebaihia M, Baker S, Basham D, Brooks K, Chillingworth T, Connerton P, Cronin A, Davis P, Davies RM, Dowd L, White N, Farrar J, Feltwell T, Hamlin N, Haque A, Hien TT, Holroyd S, Jagels K, Krogh A, Larsen TS, Leather S, Moule S, O'Gaora P, Parry C, Quail M, Rutherford K, Simmonds M, Skelton J, Stevens K, Whitehead S, Barrell BG (2001) Complete genome sequence of a multiple drug resistant Salmonella enterica serovar Typhi CT18. Nature 413: 848852.

32. McClelland M, Sanderson KE, Clifton SW, Latreille P, Porwollik S, Sabo A, Meyer R, Bieri T, Ozersky P, McLellan M, Harkins CR, Wang C, Nguyen C, Berghoff A, Elliott G, Kohlberg S, Strong C, Du F, Carter J, Kremizki C, Layman D, Leonard S, Sun H, Fulton L, Nash W, Miner T, Minx P, Delehaunty K, Fronick C, Magrini V, Nhan M, Warren W, Florea L, Spieth J, Wilson RK (2004) Comparison of genome degradation in Paratyphi A and Typhi, human-restricted serovars of Salmonella enterica that cause typhoid. Nat Genet 36: 1268-1274.

33. Mackinnon, A (2000) A spreadsheet for the calculation of comprehensive statistics for the assessment of diagnostic tests and inter-rater agreement. Comput Biol Med 30: 127134.

34. Pflumm M (2011) Speedy sequencing technologies help track food-borne illness. Nat Medicine 17: 395.

35. Kaijalainen S, Karhunen PJ, Lalu K, Lindström K (1993) An alternative hot start technique for PCR in small volumes using beads of wax-embedded reaction components dried in trehalose. Nucleic Acids Res 21: 2959-2960.

\section{Corresponding author}

Dr. Javier Garaizar

Department of Immunology

Microbiology and Parasitology

University of the Basque Country

Paseo de la Universidad 7, 01006

Vitoria-Gasteiz, Spain

Telephone: +34 945 013912; Fax: +34 945013014

Email: javier.garaizar@ehu.es

Conflict of interests: No conflict of interests is declared 